\title{
Biosynthesis, primary structure and molecular cloning of snowdrop (Galanthus nivalis L.) lectin
}

\author{
1 Laboratory for Phytopathology and Plant Protection, Catholic University of Leuven, Belgium \\ 2 Department of Biological Chemistry, University of Michigan, Ann Arbor, USA \\ ${ }^{3}$ Department of Biochemistry, Catholic University of Leuven, Belgium \\ 4 Rega Institute for Medical Research, Catholic University of Leuven, Belgium
} Els J. M. Van DAMME ${ }^{1}$, Hanae KAKU ${ }^{2}$, Fulvio PERINI ${ }^{2}$, Irwin J. GOLDSTEIN ${ }^{2}$, Ben PEETERS ${ }^{3}$, Fumio YAGI ${ }^{2}$, Benny DECOCK $^{4}$
and Willy J. PEUMANS

(Received May 17, 1991) - EJB 910652

Poly(A)-rich RNA isolated from ripening ovaries of snowdrop (Galanthus nivalis L.) yielded a single 17-kDa lectin polypeptide upon translation in a wheat-germ cell-free system. This lectin was purified by affinity chromatography. Translation of the same RNA in Xenopus leavis oocytes revealed a lectin polypeptide which was about $2 \mathrm{kDa}$ smaller than the in vitro synthesized precursor, suggesting that the oocyte system had removed a 2-kDa signal peptide.

A second post-translational processing step was likely to be involved since both the in vivo precursor and the Xenopus translation products were about $2 \mathrm{kDa}$ larger than the mature lectin polypeptide. This hypothesis was confirmed by the structural analysis of the amino acid sequence of the mature protein and the cloned mRNA.

Edman degradation and carboxypeptidase $Y$ digestion of the mature protein, and structural analysis of the peptides obtained after chemical cleavage and modification, allowed determination of the complete 105 amino acid sequence of the snowdrop lectin polypeptide. Comparison of this sequence with the deduced amino acid sequence of a lectin cDNA clone revealed that besides the mature lectin polypeptide, the lectin mRNA also encoded a 23 amino acid signal-sequence and a C-terminal extension of 29 amino acids, which confirms the results from in vitro translation experiments.

Lectins are a heterogeneous class of (glyco)proteins grouped together based on their ability to recognize and bind carbohydrate moieties of glycoconjugates. Although numerous plant lectins have been isolated and characterized in detail, the physiological function of these proteins remains unclear (Etzler, 1986). A study of the biosynthesis of lectins and their subsequent subcellular deposition can be helpful in obtaining a better understanding of the molecular biology of lectins. In combination with physiological studies of the lectins concerned (e.g. occurrence and abundance of lectin in different plant tissues) it is possible to obtain important information in a search for the normal biological function of these proteins.

A few years ago a mannose-specific lectin was isolated from bulbs of snowdrop (Galanthus nivalis) (Van Damme et al., 1987). The G. nivalis agglutinin is a tetrameric protein composed of identical $12.5-\mathrm{kDa}$ subunits, which is devoid of carbohydrate. In recent years similar lectins have been found in bulbs of all representatives of the plant family Amaryllidaceae, e.g. Narcissus (Van Damme et al., 1988). Furthermore we have shown that these lectins are found in

Correspondence to E. J. M. Van Damme, Catholic University Leuven, Laboratory for Phytopathology and Plant Protection, Willem de Croylaan 42, B-3001 Leuven, Belgium

Abbreviations: GNA, Galanthus nivalis agglutinin (lectin); Pth, phenylthiohydantoin.

Note. The novel nucleotide sequence reported in this paper has been deposited with the Genbank ${ }^{\mathrm{TM}} / \mathrm{EMBL}$ Data library and is available under accession number iM 55556. almost all plant tissues where they represent the most prominent proteins at certain developmental stages of the plant (Van Damme and Peumans, 1990). Amaryllidaceae lectins have been found to be very useful tools for the analysis and purification of glycoproteins (Shibuya et al., 1988). Moreover they are very potent and selective inhibitors of retroviruses and cytomegalovirus in vitro (Balzarini et al., 1990).

A recent study of the in vivo biosynthesis of the snowdrop lectin in ripening ovaries has shown that it is synthesized on the rough endoplasmic reticulum as a higher molecular-mass precursor $(15 \mathrm{kDa})$ which is post-translationally converted into the mature 12.5-kDa lectin polypeptide (Van Damme and Peumans, 1988). We report here the in vitro translation and processing of the snowdrop lectin, and the isolation of the in vivo synthesized lectin precursor. Furthermore we show that the complete amino acid sequence of the mature protein as obtained from structural protein analysis and the sequence of the precursor as deduced from the nucleotide sequence of its cloned mRNA.

\section{EXPERIMENTAL PROCEDURES}

\section{Materials}

Flowering plants and snowdrop bulbs ( $G$, nivalis L.) were collected from a local garden and purchased from a local store, respectively. Oligo-deoxythymidine cellulose and an SDS molecular-mass kit were purchased from Sigma Chemical 
Co. (St Louis, MO). Radioisotopes were obtained from the Amersham Corp. A cDNA synthesis kit, the multifunctional phagemid $\mathrm{pT}_{7} \mathrm{~T}_{3} 18 \mathrm{U}$, restriction enzymes and DNA-modifying enzymes were obtained from Pharmacia LKB Biotechnology Inc. Escherichia coli XL1 Blue competent cells were purchased from Stratagene (La Jolla, CA). Cyanogen bromide was purchased from Kodak Laboratory and Research products (Rochester, NY). Trypsin treated with tosylphenylalanylchloromethane was obtained from Worthington Biochemical Co. (Freehold, NJ). Carboxypeptidase Y was obtained Boehringer Mannheim GmbH (Federal Republic of Germany).

\section{Lectin isolation}

The snowdrop lectin (GNA) was isolated from extracts of bulbs by affinity chromatography on immobilized mannose as reported previously (Van Damme et al., 1987) followed by gel filtration on Sephacryl S-200 $(1.5 \times 120 \mathrm{~cm})$, eluting with $6 \mathrm{M}$ guanidinium $/ \mathrm{HCl}$. The lectin fraction was dialyzed against distilled water and lyophilized. Sequence analysis was performed on a sample of snowdrop lectin purified by affinity chromatography on Synsorb - mannose followed by gel filtration on Sephacryl S-200 in $6 \mathrm{M}$ guanidine $/ \mathrm{HCl}$.

\section{$R N A$ isolation}

Total cellular RNA was prepared from ovary tissue (stored at $-80^{\circ} \mathrm{C}$ ) essentially as described by Finkelstein and Crouch (1986). Poly(A)-rich RNA was enriched by chromatography on oligo-deoxythymidine cellulose as described by Siflow et al. (1979) except that poly(A)-rich RNA was eluted at room temperature. A second chromatography of the RNA on the same column was performed after $\mathrm{Me}_{2} \mathrm{SO}$ treatment of the RNA.

\section{Protein synthesis in the wheat-germ cell-free extract}

Poly(A)-rich RNA was translated in a wheat-germ cellfree extract which was prepared as described previously (Peumans et al., 1982) except that the homogenization buffer contained $6 \mathrm{mM}$ 2-mercaptoethanol and an additional $15 \mathrm{mM}$ magnesium acetate. In the presence of a higher concentration of these divalent cations, most of the endogenous messenger ribonucleoproteins from large aggregates which will sediment during the subsequent centrifugation of the homogenate (Peumans et al., 1980). The incubation mixture for cell-free translation contained $/ \mathrm{ml}: 0.4 \mathrm{ml}$ extract, $20 \mathrm{mM}$ Hepes $/ \mathrm{KOH}$ pH $8.0,90 \mathrm{mM}$ potassium acetate, $2.5 \mathrm{mM}$ magnesium acetate, $1 \mathrm{mM}$ ATP, $20 \mu \mathrm{M}$ GTP, $25 \mu \mathrm{g} / \mathrm{ml}$ creatine kinase, $8 \mathrm{mM}$ creatinephosphate, $2 \mathrm{mM}$ dithiothreitol, $0.4 \mathrm{mM}$ spermidine, 19 unlabeled amino acids $(100 \mu \mathrm{M}$ each) and $50 \mu \mathrm{Ci}$ $\left[{ }^{35} \mathrm{~S}\right]$ methionine or $100 \mu \mathrm{Ci}\left[{ }^{3} \mathrm{H}\right]$ leucine. Prior to adding the mRNA ( $30 \mu \mathrm{g} / \mathrm{ml}$ final concentration) and the labeled amino acid, the cell-free translation system was incubated for $15 \mathrm{~min}$ at room temperature to reduce the endogenous template activity of the system. Subsequently the reaction mixtures were incubated for $1 \mathrm{~h}$ at $25^{\circ} \mathrm{C}$ and the incorporation of labeled amino acid into trichloroacetic-acid-insoluble material determined.

\section{Isolation and characterization \\ of the in vitro synthesized lectin polypeptides}

Lectin isolation from the in vitro translation mixture was accomplished either by affinity chromatography on man-
nose-Sepharose, single or double immunoprecipitation or immunoaffinity chromatography. Whenever microsomal membranes or organelles were present in the incubation mixture they were disrupted using 1\% Triton X-100 prior to the isolation of the lectin. Affinity chromatography on mannose-Sepharose was carried out in the presence of $0.5 \mathrm{M}$ ammonium sulphate (as described by Van Damme and Peumans, 1988) or NaCl/Pi (1.5 mM $\mathrm{KH}_{2} \mathrm{PO}_{4} / 10 \mathrm{mM}$ $\mathrm{Na}_{2} \mathrm{HPO}_{4} / 3 \mathrm{mM} \mathrm{KCl} / 140 \mathrm{mM} \mathrm{NaCl}, \mathrm{pH}$ 7.4). The lectin was desorbed using unbuffered $20 \mathrm{mM}$ 1,3-diaminopropane.

Small aliquots were withdrawn for determination of $\left[{ }^{3} \mathrm{H}\right]$ leucine or $\left[{ }^{35} \mathrm{~S}\right]$ methionine incorporation. The lectin was subsequently analyzed by SDS/PAGE on $12.5-25 \%$ acrylamide gradient gels using a discontinuous system as described by Laemmli (1970). After fixing and destaining, gels were immersed in $1 \mathrm{M}$ sodium salicylate for $30 \mathrm{~min}$, dried under partial vacuum and exposed to X-ray films (Fuji RX, Japan) at $-80^{\circ} \mathrm{C}$.

\section{Protein synthesis after injection of $\mathrm{X}$. laevis oocytes}

Frogs were anaesthesized by immersion in a $0.1 \%$ solution of MS-222 or Metacaini Mesylas in water for $30 \mathrm{~min}$. An ovary lob was surgically removed and transferred to Barth's solution. Oocytes were manually defolliculated and stored in Barth's solution at $18^{\circ} \mathrm{C}$. Groups of ten oocytes were microinjected with $1 \mu \mathrm{g}$ poly(A)-rich RNA each and incubated $100 \mu \mathrm{l}$ Barth's medium containing $25 \mu \mathrm{Ci}\left[{ }^{3} \mathrm{H}\right]$ leucine. After incubation for $24-28 \mathrm{~h}$ at $18^{\circ} \mathrm{C}$, oocytes were homogenized in $10 \mathrm{mM}$ Tris $/ \mathrm{HCl} \mathrm{pH} 7.6$ containing $150 \mathrm{mM} \mathrm{NaCl}, 1 \mathrm{mM}$ EDTA, $0.5 \%$ sodium desoxycholate, $0.5 \%$ Triton $\mathrm{X}-100$, $0.1 \%$ SDS and $0.2 \mu \mathrm{g} / \mathrm{ml}$ Trasylol. Afterwards the suspension was centrifuged at $10000 \mathrm{~g}$ for $10 \mathrm{~min}$ and the lectin isolated by affinity chromatography on mannose-Sepharose in the presence of $0.5 \mathrm{M}$ ammonium sulphate.

\section{Isolation of the in vivo lectin precursor}

Snowdrop ovaries were homogenized as reported previously (Van Damme and Peumans, 1988). The organelles were separated from the soluble proteins and small molecules on a Sepharose $4 \mathrm{~B}$ column $(5 \times 30 \mathrm{~cm})$ as described by Van der Wilden et al. (1980). Fractions containing the organelles were pooled and brought to $0.5 \%$ Triton $X-100$ and $0.5 \mathrm{M}$ ammonium sulphate. The lectin was isolated by affinity chromatography on mannose - Sepharose.

\section{Isolation of microsomal membranes}

Microsomal membranes fron dog pancreas were prepared essentially as described by Shields and Blobel (1978).

\section{Amino acid sequence analysis}

Protein sequencing was conclucted on an Applied Biosystems (Foster City, California, USA) Model 470 A protein sequencer interfaced with an Applied Biosystems model $120 \mathrm{~A}$ on-line analyzer.

\section{Cyanogen bromide cleavage and isolation of peptides}

Snowdrop lectin (10 mg) dissolved in $0.5 \mathrm{ml} \mathrm{70 \%} \mathrm{(by} \mathrm{vol.)}$ formic acid was added to a cyanogen bromide solution $(10 \mathrm{mg}$ / $0.7 \mathrm{ml}$ formic acid) and the reaction mixture was incubated for $24 \mathrm{~h}$ at $25^{\circ} \mathrm{C}$. After degasing by water vacuum, the solution 
was diluted tenfold with distilled water and lyophilized. The resulting peptides were dissolved in $0.2 \mathrm{M}$ acetic acid, the insoluble material was removed by centrifugation and the solution applied to a Bio-Gel P-6 gel-filtration column $(2.5 \times 105 \mathrm{~cm})$, eluting with $0.2 \mathrm{M}$ acetic acid. The peptide fractions were monitored by ultraviolet absorption at $230 \mathrm{~nm}$ and $280 \mathrm{~nm}$. The combined fractions M1 (tubes $65-70$ ) and M2 (82-95, see Fig. 5) were dialyzed against distilled water using spectrapor MWCO:1000 and lyohilized.

\section{Acetylation of $M I$ peptide}

Acetylated M1 $(0.5 \mathrm{mg})$ was prepared by the addition of pyridine $(300 \mu \mathrm{l})$ and acetic anhydride $(150 \mu \mathrm{l})$ followed by incubation for $15 \mathrm{~h}$ at $25^{\circ} \mathrm{C}$. After removal of pyridine by repeated evaporation with the concomitant addition of water (4 times), the acetylated M1 peptide was lyophilized.

\section{SDS/urea/polyacrylamide gel electrophoresis}

$12.5 \%$ SDS/urea/PAGE was performed using the procedure of Swank and Munkres (1971). Each fraction, (M1 and M2) was applied to the $12.5 \%$ SDS/urea/acrylamide gel using the SDS molecular-mass-marker kit as standard (myoglobin, $16950 ; 14400 ; 8160 ; 6210 ; 2510 \mathrm{Da})$. The polyacrylamide gel was stained with Coomassie brilliant blue.

\section{Carboxypeptidase- $Y$ digestion}

Carboxypeptidase $\mathrm{Y}$ was added to GNA and the M1 peptide solution in $10 \mathrm{mM}$ sodium phosphate buffer, $\mathrm{pH} 7.0$. After incubation at $25^{\circ} \mathrm{C}$ for $5 \mathrm{~min}$ and $30 \mathrm{~min}$, the reaction was stopped by adding 10\% trichloroacetic acid (5\% final concentration) and the precipitate was removed by centrifugation. The free amino acid composition in the supernatant was analyzed.

\section{Reduction and alkylation}

GNA and the M1 peptide were dissolved in $0.1 \mathrm{M}$ ammonium bicarbonate containing $6 \mathrm{M}$ guanidine $/ \mathrm{HCl}, \mathrm{pH} 8.1$. A tenfold excess of 2-mercaptoethanol over the estimated cysteine concentration was added to the protein solution and the reaction mixture was incubated at $50^{\circ} \mathrm{C}$ for $3 \mathrm{~h}$. A 2.5 fold excess of 4-vinylpyridine or iodomethane [ $20 \%$ (by vol.) in methanol] over 2-mercaptoethanol was added to the reaction mixture and alkylation was allowed to proceed for $1 \mathrm{~h}$. The samples were dialyzed against distilled water $(3 \times)$ and lyophilized. The pyridylethylated protein was used for sequencing while the methylated form was used for amino acid analysis.

\section{Amino acid analysis}

Aliquots of reduced and methylated sample were hydrolyzed in teflon-lined screw-capped culture tubes, in $6 \mathrm{M}$ $\mathrm{HCl}$ for $24 \mathrm{~h}$ under an atmosphere of nitrogen. The acid was evaporated under a stream of nitrogen. The sample was reconstituted in $0.2 \mathrm{M}$ sodium citrate, $\mathrm{pH}$ 2.6. Separation was achieved on a Kratos amino acid analysis system with Beckman $110 \mathrm{~A}$ pumps, on a $46 \times 120 \mathrm{~mm}$ Interaction (Los Altos, CA) cation-exchange column (sodium form). The buffers for the three-step gradient $(\mathrm{pH} 3.28,4.25$ and 7.40) were purchased from Pickering Labs (Mountain View, CA).
Post-column derivatization with sodium hypochlorite and 0 phtaldehyde was according to Fujwwara et al. (1987).

\section{Construction and screening of the cDNA library}

A cDNA library was constructed from total poly(A)-rich mRNA isolated from snowdrop ovaries using the cDNA synthesis kit from Pharmacia. cDNA fragments were inserted into the EcoRI site of the multifunctional phagemid $\mathrm{pT}_{7} \mathrm{~T}_{3}$ $18 \mathrm{U}$. The library was propagated in $E$. coli XL1 Blue.

Recombinant lectin clones were screened by colony hybridization using a ${ }^{32} \mathrm{P}$-end-labeled degenerate oligonucleotide probe (15-mer, 5' TGT GTT TGT T/A/GGC CCA $3^{\prime}$ ) derived from residues $41-45$ of a partially known amino acid sequence for the lectin (Fig. 4). Hybridization was carried out overnight at $38^{\circ} \mathrm{C}$ in $0.9 \mathrm{M}$ sodium chloride containing $90 \mathrm{mM}$ Tris/ $\mathrm{HCl}$ pH 7.5, $6 \mathrm{mM}$ EDTA, $10 \times$ Denhardt's solution, $0.1 \% \mathrm{SDS}, 180 \mu \mathrm{g} / \mathrm{ml}$ hydrolyzed yeast RNA and $2 \times 10^{6}$ $\mathrm{cpm} / \mathrm{ml}{ }^{32} \mathrm{P}$-labeled probe. Hybridization filters were then washed four times in $6 \times \mathrm{NaCl} / \mathrm{Cit}(1 \times \mathrm{NaCl} / \mathrm{Cit}, 0.9 \mathrm{M}$ sodium chloride and $0.09 \mathrm{M}$ sodium citrate, $\mathrm{pH} 7.0$ ) at room temperature for $15 \mathrm{~min}$, followed by a 5 -min wash at hybridization temperature in $6 \times \mathrm{NaCl} / \mathrm{Cit}$. Filters were blotted dry, wrapped in Saran Wrap and exposed to Kodak X-Omat $S$ film at $-80^{\circ} \mathrm{C}$. Colonies that produced positive signals were selected and rescreened at low density using the same conditions. Plasmids were isolated from purified single colonies on a miniprep scale using the alkaline lysis method as described by Mierendorf and Pfeffer (1987) and sequenced by the dideoxy method (Sanger et al., 1977).

\section{Computer analyses}

Comparison of the amino acid sequence of the snowdrop lectin to the lectins from several mannose-binding proteins from plants, animals and bacteria was conducted with protein sequence data NBRF (Protein Sequence Database of the protein identification resource, National Biomedical Research Foundation). DNA sequences were analyzed using programs from PC Gene and Genepro.

\section{RESULTS AND DISCUSSION}

In vitro translation of poly $(A)$-rich $m R N A$

in a wheat-germ cell-free system

Poly(A)-rich RNA isolated from ovaries of snowdrop was translated in a wheat-germ cell-free system. Afterwards the lectin was isolated by affinity chromatography on mannoseSepharose. As shown in Fig. 1 a single polypeptide with an apparent molecular mass of approximately $17 \mathrm{kDa}$ is retained on the column. Compared to the in vivo precursor which has a molecular mass of $15 \mathrm{kDa}$ (Van Damme and Peumans, 1988) it seems likely that the lectin is synthesized in vitro with a signal peptide.

Fractionation of the total wheat-germ translation mixture on a gel-filtration Superose 12 column (Pharmacia LKB Biotechnology Inc.) revealed the highest concentration of in vitro lectin precursor in fractions $33-34$ whereas the mature lectin $(50 \mathrm{kDa})$ elutes in fraction 39 , as determined in a separate run, indicating that the lectin precursor has a higher molecular mass (Fig. 2). From this experiment it can be concluded that the in vitro synthesized precursor of the snowdrop lectin does not occur as a monomer but is an oligomer containing four precursor chains. 


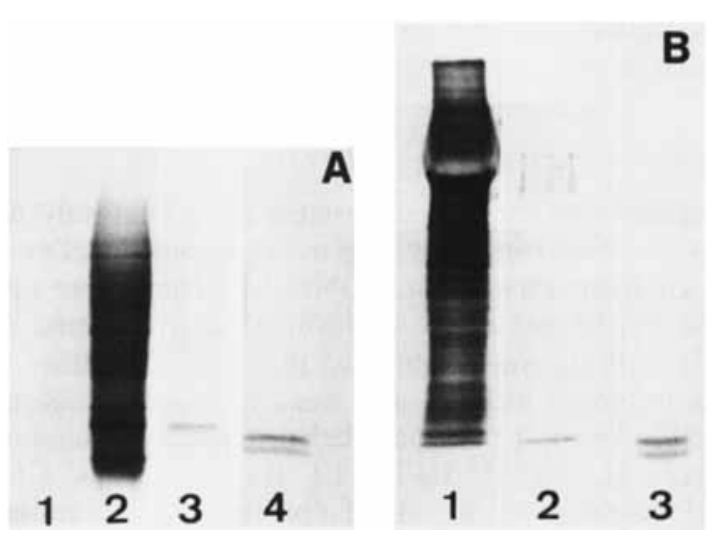

Fig. 1. Fluorograph of translation products of poly $(A)$-rich $R N A$ from snowdrop in a wheat-germ cell-free system $(A)$ and Xenopus oocyles $(B)$. (A) Lane 1, endogenous products of the wheat-germ cell-free system; lane 2, total homogenate of translation products synthesized in response to poly(A)-rich RNA from snowdrop; lane 3, affinitypurified lectin polypeptide from translation products of a wheat-germ system; lane 4, in vivo labeled precursor and lectin polypeptides. (B) Lane 1, total homogenate of proteins from Xenopus oocytes injected with poly(A)-rich mRNA isolated from snowdrop; lane 2, affinity purified lectin from Xenopus oocytes; lane 3, in vivo labeled precursor and lectin polypeptides

\section{Isolation of the lectin synthesized in vitro}

In a previous paper we have shown that the lectin synthesized in in vivo labeling experiments could easily be isolated by affinity chromatography on mannose - Sepharose in the presence of $0.5 \mathrm{M}$ ammonium sulphate (Van Damme and Peumans, 1988). However, for some unknown reason the in vitro synthesized lectin was poorly retained on the column in the presence of ammonium sulphate. When affinity chromatography was performed in $\mathrm{NaCl} / \mathrm{Pi}$ the in vitro lectin polypeptides readily bound to the affinity matrix. It appears that both the in vivo and the in vitro synthesized precursor exhibit the same carbohydrate-binding activity as the lectin itself. Therefore the sequence which is cleaved off when the precursor is processed into the lectin is not essential for the carbohydrate-binding properties of the lectin precursor.

Besides affinity chromatography on mannose-Sepharose, the lectin can also be isolated by immunoprecipitation or immunoaffinity chromatography. However, when precipitating lectin polypeptides from a wheat-germ extract, nonspecific reactions often occur. By adding detergents to the cellfree system and the washing solutions it was possible to reduce the non-specific binding but not to abolish it completely.

\section{Cell-free protein synthesis in the presence of microsomes}

Many secretory proteins or proteins which are found in specific locations in the cell are synthesized with an $\mathrm{N}$-terminal signal sequence which is proteolytically cleaved off in vivo before the synthesis of the polypeptide is completed. To investigate whether the snowdrop lectin is also synthesized with such an extra signal sequence, in vitro translation experiments in the presence of microsomes were carried out.

When a wheat-germ cell-free system was supplemented with dog pancreas microsomes there was no visible change in molecular mass of the lectin precursor on the fluorogram. However, when a wheat-germ extract was prepared from developing embryos (which have an extended network of rough

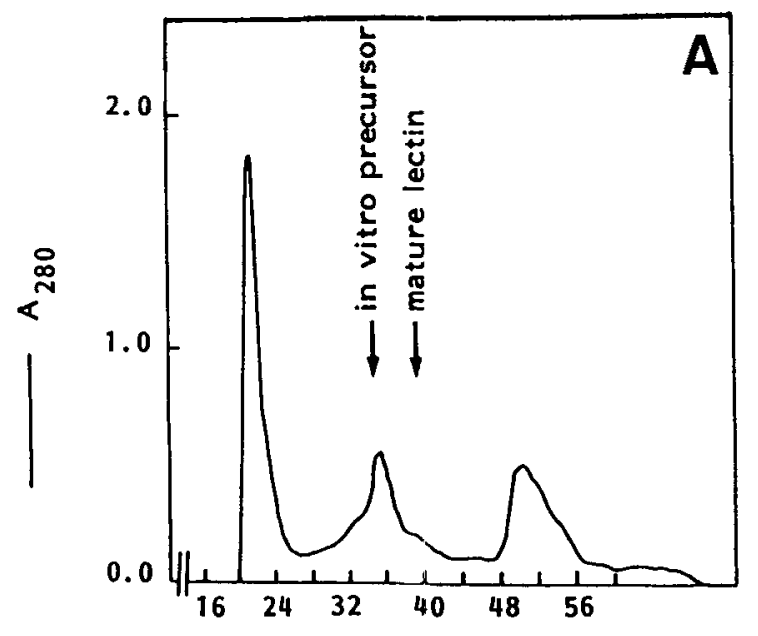

Fraction number

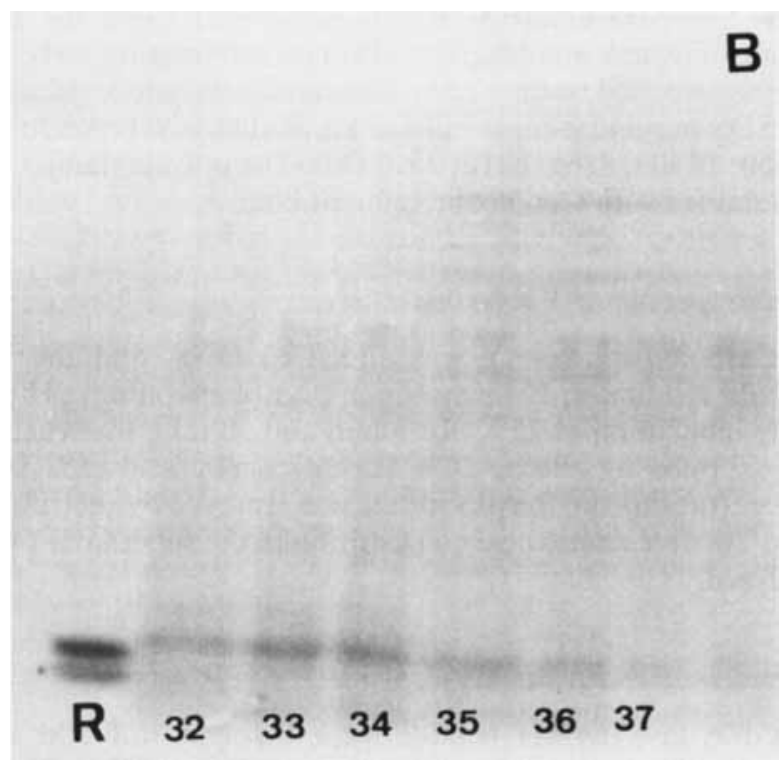

Fig. 2. Gel filtration on a Superose 12 column of a total wheat-germ cell-free system after translation of poly $(A)$-rich RNA from snowdrop (A). Fractions of $300 \mu \mathrm{l}$ were collected and the lectin immunoprecipitated. The elution position of the lectin was determined in a separate run. $\mathrm{NaCl} / \mathrm{P}_{\mathrm{i}}$ containing $0.2 \mathrm{M}$ mannose was used as running buffer. The flow rate was $20 \mathrm{ml} / \mathrm{h}$. Lectin polypeptides were immunoprecipitated and analyzed ty SDS/PAGE and subsequently by fluorography (B). The numbers under each lane correspond to the fraction number shown in $A$. In lane $R$ in vivo labeled precursor and lectin were run

endoplasmic reticulum) and used in in vitro translation experiments, two polypeptide bands with molecular masses of $17 \mathrm{kDa}$ and $15 \mathrm{kDa}$ appeared on the autofluorogram indicating that the lectin is partially processed (results not shown). Since these e;periments were highly dependent on the batch of embryos used, we tried to confirm the existence of a signal peptide by synthesizing the lectin in Xenopus oocytes.

\section{Lectin polypeptides synthesized in Xenopus oocytes}

In order to determine whether $X$. laevis oocytes are able to synthesize the snowdrop lectin they were injected with 


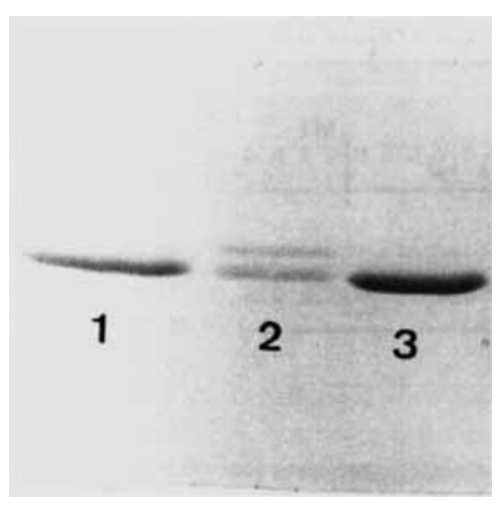

Fig. 3. SDS/PAGE of the in vivo synthesized lectin in snowdrop ovaries. Lane 1, lectin isolated from the soluble fraction; lane 2, lectin isolated from the organelle fraction; lane 3 , snowdrop lectin

poly(A)-rich RNA isolated from snowdrop ovaries. After $26 \mathrm{~h}$ of incubation, in the presence of $\left[{ }^{3} \mathrm{H}\right]$ leucine, oocytes were homogenized and lectin isolated by affinity chromatography on mannose - Sepharose. As shown in Fig. 1 Xenopus oocytes synthesized a lectin polypeptide with a molecular mass of $15 \mathrm{kDa}$. Since it is generally accepted that oocytes can process plant preprotein polypeptides (Larkins et al., 1979; Boston et al., 1982) we assume that the signal sequence had been cleaved off. Xenopus oocytes have also been shown to secrete both animal secretory proteins (Lane, 1981) and intracellularly deposited plant proteins (Bassuner et al., 1983) when injected with the corresponding mRNA. However, different proteins are exported at intrinsically different rates (Colman and Morser, 1979). Although it has been reported before that the snowdrop lectin is synthesized on the rough endoplasmic reticulum (Van Damme and Peumans, 1988) and is probably located in protein bodies as is the case for many other lectins and storage proteins, we found no evidence for secretion of the lectin at least not within the incubation period of $26 \mathrm{~h}$ (results not shown).

\section{Isolation of the in vivo lectin precursor}

A lectin fraction enriched in precursor was isolated from the organelle fraction of snowdrop ovaries by affinity chromatography on mannose - Sepharose. As shown on SDS/ PAGE (Fig. 3) the lectin isolated from this fraction contains both the mature lectin and the lectin precursor. The soluble fraction, however, only contains the mature lectin polypeptide.

$\mathrm{N}$-terminal amino acid sequence analysis of the lectin preparation containing both the lectin precursor and the mature lectin revealed only one sequence. Since this amino acid sequence is identical to that of an independently sequenced single isolectin of snowdrop (results not shown) we can conclude that both the mature lectin and the in vivo lectin precursor contain the same $\mathrm{N}$-terminal sequence unless the precursor polypeptide is blocked. Since no evidence could be obtained for glycosylation of any of the precursor forms (results not shown) we assume that the in vivo synthesized precursor will have an additional sequence at the $C$ terminus which can account for the $2-\mathrm{kDa}$ difference in molecular mass found between the mature lectin polypeptide and both the in vivo precursor and the Xenopus transiation products.

\section{Structural analysis of the mature protein}

Using chemical cleavage and modification, and both trypsin and carboxypeptidase $\mathrm{Y}$ digestion, the complete amino acid sequence of the snowdrop lectin was determined. As shown in Fig. 4, the complete amino acid sequence of GNA consists of 105 amino acid residues/subunit. The snowdrop lectin is a pure tetrameric protein rich in asparagine, glycine and leucine, and contains three cysteine residues. Based on the amino acid sequence composition, the molecular mass of GNA was calculated to be $11724 \mathrm{Da}$. This GNA protein was readily and directly sequenced up to residue 57 . However, four amino acid residues between residue 51 and 54 were ambiguous in the first sequencing.

GNA contains two methionine residues/subunit located at positions 25 and 56. Therefore the cleavage of methionine residues of GNA using cyanogen bromide is a convenient way for separating the large GNA C-terminal peptide from the two N-terminal small peptides (Fig. 4). The elution profile of GNA on a Bio-gel P-6 gel-filtration column following treatment with cyanogen bromide reagent is shown in Fig. 5. Two peptide fractions were obtained: $\mathrm{M} 1$, obtained by combining fractions $65-70$ and $\mathrm{M} 2$, obtained from fractions 82-95. The molecular size of M1 and M2, calculated from SDS/urea $(12.5 \%)$ PAGE appeared to be approximately $4.2 \mathrm{kDa}$ and $2.0 \mathrm{kDa}$, respectively. However, M2 contained two peptides (M2-1 and M2-2), which consist of position 1-25 (M2-1) and $26-56$ (M2-2). We were unable to separate these peptides; hence, they were sequenced simultaneously. The results indicate that they were present in equimolar amounts and correspond to the N-terminal sequence of $1-56$.

M1, which represents the C-terminal peptide isolated from methionine cleavage of GNA by cyanogen bromide incubation, was sequenced from the glutamine residue at position 57 to the arginine residue at position 101. Moreover, digestion of the intact protein and peptide M1 with caboxypeptidase $Y$ yielded mostly two amino acids, suggesting that the C-terminal sequence was Thr-Gly.

Acetylation of $\mathrm{M} 1$ blocked two lysyl residues at positions 70 and 90 , protecting them from tryptic digestion, while blocking the $\mathrm{N}$-terminal residue at position 57 of the M1 peptide. Trypsin cleaved acetylated $\mathrm{M} 1$ at arginines 92 and 101 , yielding an $\mathrm{N}$-terminally blocked peptide encoding residues 57-92 and two small peptides which were not separated. Sequencing the mixture confirmed the 93-101 sequence (MA-1 fragment) already determined from the intact peptide M1. A new sequence which contained the two C-terminal amino acids of $\mathrm{M} 1$ (and of the intact lectin) formed fragment MA-2 (residues 102-105).

Two cysteines were assigned to peptide M2-2. If the peptide was alkylated with vinylpyridine in the absence of reductant, only background was found at residues 29 and 52, while PthPro-Glu-Cys (PTH, phenylthiohydantoin) was detected at both positions after reduction and alkylation, indicating that a disulfide bond existed between the two cysteines. We must note that this disulfide bond is very difficult to reduce in the intact protein. However, when M1 was alkylated without prior reduction, Pth-Pro-Glu-Cys was found at residue 86 , indicating the presence of free cysteine. The disulfide bond does not appear to be involved in sugar binding inasmuch as GNA containing $10 \%$ dithiothreitol did not lose its precipitating activity with Saccharomyces cerevisiae yeast $\alpha$-mannan.

Several instances of micro-heterogeneity of the GNA amino acid sequence were found at positions 51 ( $\mathrm{S}$ or $\mathrm{H}), 53$ ( $F$ or $\mathrm{Y}$ ) and 86 ( $\mathrm{S}$ or $\mathrm{C}$ ). This is not surprising since the lectin 


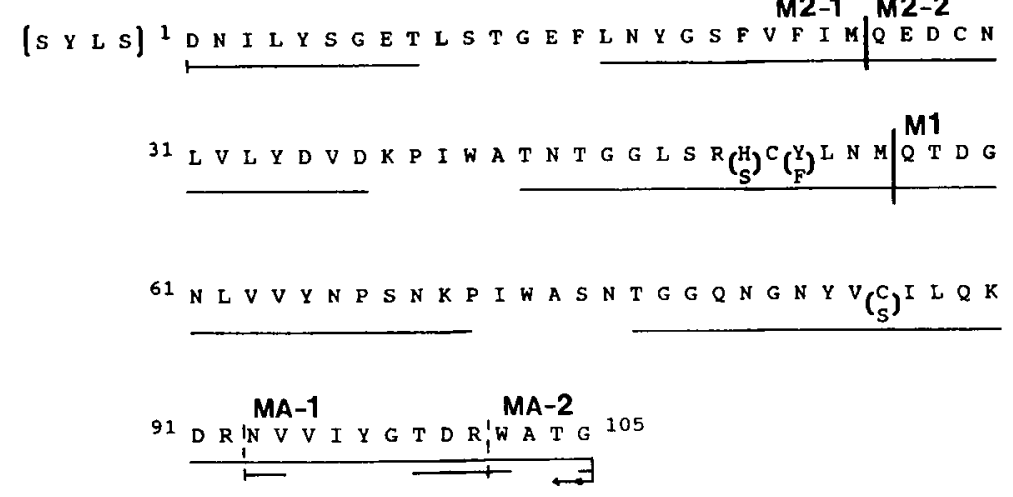

Fig. 4. Complete amino acid sequence of the snowdrop lectin. (-) Extent of the fragments used to construct the sequence, assignment of residues by amino acid sequencing; $(\leftarrow)$ results of carboxypeptidase $Y$ digestion; open parentheses (), possission of heterogeneity of amino acid residue. Solid vertical lines (|) show points of cleavage by cyanogen bromide. Dotted vertical lines (i) show points of cleavage by trypsin on peptide $\mathrm{M} 1$

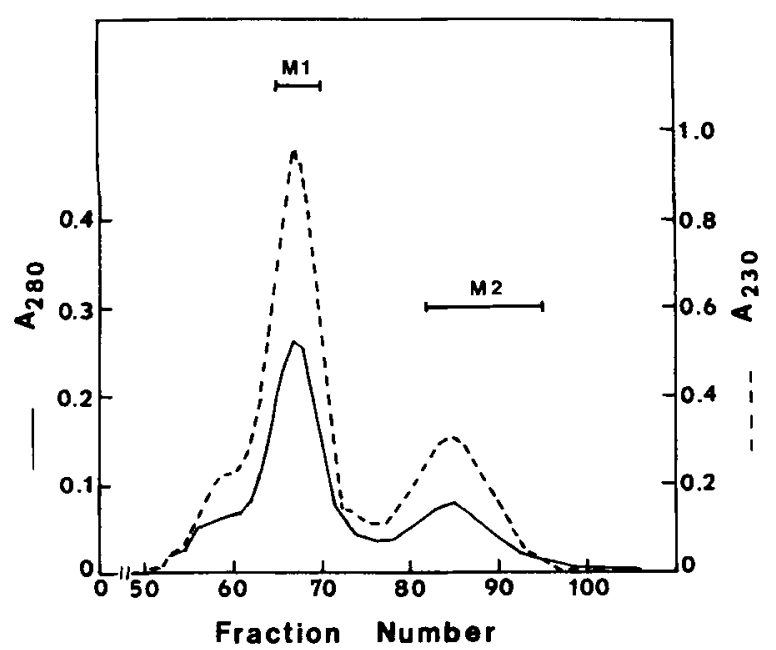

Fig. 5. Elution pattern of cyanogen bromide fragments of snowdrop lectin on a column of Bio-Gel P-6 $(2.5 \times 105 \mathrm{~cm})$ in $0.2 \mathrm{M}$ acetic acid

is a very complex mixture of isolectins as was shown upon analysis of the purified protein by ion-exchange chromatography or isolectric focusing (Van Damme et al., 1988). Moreover we now have evidence for the occurrence of multiple isoforms at the molecular level since different lectin cDNA clones which definitely differ in their amino acid sequence have been isolated (E. Van Damme, unpublished results). Moreover, $30 \%$ of GNA possessed four more amino acids (Ser-Tyr-Leu-Ser) at the $\mathrm{N}$-terminal amino acid residue (Fig. 4). It is suggested that these two GNA amino acid sequences undergo differential enzyme processing during their differentiation.

Interestingly a portion of amino acid sequence of Met25Gly47 has strong identity between Met56-Gly79 and Gln 89 - Thr 104 , showing $70 \%$ and $35 \%$ identity, respectively (Fig. 6).

\section{Characterization of the snow'drop lectin cDNA}

In order to confirm the existence of a pre-proform of the lectin, a cDNA library was constructed in the multifunctional phagemid $\mathrm{pT}_{3} \mathrm{~T}_{7} 18 \mathrm{U}$ using poly(A)-rich RNA isolated from

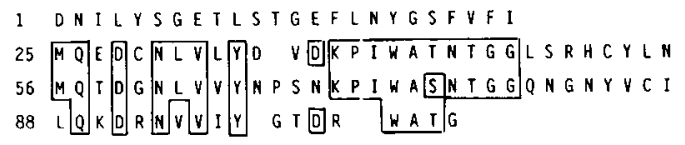

Fig. 6. Internal homology of segments $25-47,56-79$ and $89-104$ of the snowdrop lectin sequence

snowdrop ovaries. The nucleotide sequence of the cDNA lectin clone selected by colony hybridization and the deduced amino acid sequence are depicted in Fig. 7. The lectin clone contains a 570-bp open-reading frame with one possible initiation codon at position 18. Translation starting with this codon generates a 157 amino acid polypeptide with a calculated molecular mass of $16917 \mathrm{Da}$, corresponding in size to the in vitro translation product for the snowdrop lectin. The $3^{\prime}$ untranslated region contains six in-frame termination codons and one potential polyadenylation signal at position 532 . Although the cDNA library was constructed using an oligodT primer for first strand synthesis, the lectin clone has no poly(A) tail.

Using the rules for protein processing of Von Heijne (1986) three possible cleavage sites were identified between residues 18 and 19 , residues 19 and 20 , and residues 23 and 24 of the amino acid sequence deduced from the cDNA clone. Processing of the signal peptide at the most probable cleavage site between residues 23 and 24 (following the rules of Von Heijne) generates a lectin polypeptide with a calculated molecular mass of $14602 \mathrm{Da}$ starting with the first amino acid of the protein and will account for a $2315-\mathrm{Da}$ decrease in molecular mass upon transport of the polvpeptide across the endoplasmic reticulum. Cleavage of the signal peptide between residues 19 and 20 will generate a lectin polypeptide possessing four amino acids more at the $\mathrm{N}$ terminal, as found in protein sequence determinations.

Comparison of the C-terminal-deduced amino acid sequence of both the lectin clone and the protein reveals that the first stop codon occurs 29 amino acids further downstream of Gly105. Therefore we assume that a C-terminal extension (2944 Da) is removed during post-translational processing of the protein. The hydrophobic character of this C-terminal peptide is consistent with the possibility that it is removed post-translationally. The loss of $\mathrm{C}$-terminal extensions has 
CAACTACAAGTTACAAA ATG GCT AAG GCA AGT CIC CTC AIT TIG GCC GCC ATC IIC CTT Met Ala Lys Aix Ser Leu Leu lle Leu Ala Ala lle Phe Leu

GGT GTC ATC aCA CCA TCT TGC CIG AGT GAC aAt AIT TIG TAC TCC GGT GAG ACT CIC ICT Gly Val lle Thr Pro Ser Cys Leu Ser Asp Asn lle Leu Tyr Ser Gly Glu Thr Leu Ser

ACA GGG GAA IIT CIC AAC TAC GGA AGT IIC GTT TTT ATC ATG CAA GAG GAC TGC AAT CTS Thr Gly Giu Phe Leu Asn Jyr Gly Ser Phe Val Phe Ile Met Gln Glu Asp Cys Asn Leu

GTC TTG TAC GAC GTG GAC AAG CCA ATC TGG GCA ACA AAC ACA GGT GGT CTC TCC CGT AGC Val Leu Tyr Asp Val Asp Lys Pro lle Trp Ala Thr Asn Thr Gly Gly Leu Ser Arg Ser

TGC TTC CTC AGC ATG CAG ACT GAT GGG AAC CTC GTG GTG TAC AAC CCA TCG AAC AAA CCG Cys Phe Leu Ser Met Gin Thr Asp Gly Asn Leu Val Val Tyr Asn Pro Ser Asn Lys Pro

ATT TGG GCA AGC AAC ACT GGA GGC CAA AAT GGG AAT TAC GTG TGC ATC CTA CAG AAG GAT Ile Trp Ala Ser Asn Thr Gly Gly Gln Asn Gly Asn Tyr Val Cys lle Leu Gin Lys Asp

AGg aAT GIT GTG ATC TAC GGA ACT GAT CGT TGG GCT ACT GGA ACT CAC ACC GGA CTT GTT Arg Asn Val Val Ile Tyr Gly Thr Asp Arg Trp Ala Thr Gly Thr His Thr Gly Leu Val

GGA AII CCC GCA TCG CCA CCC TCA GAG AAA TAT CCT ACT GCT GGA AAG ATA AAG CTT GTG Gly lle Pro Ala Ser Pro Pro Ser Glu Lys Tyr Pro Thr Ala Gly Lys lle Lys Leu Val

ACG GCA AAG TAA TGA CCGGTGATCTTTTAACTIGCATGTATGGgGGaAGAGTAATAAAATAAGTGCATTTGAGA Thr Ala Lys

TAATCGACCICGICGCO

Fig. 7. Nucleotide sequence and deduced amino acid sequence of snowdrop lectin cDNA clone LECGNA 2. The putative processing sites for the signal sequence and the C-terminal extension, are indicated by arrowheads. Two stop codons at the end of the coding region are indicated with squares. The potential polyadenylation site is underlined

been reported for several plant lectins [wheat germ agglutinin B, Raikhel and Wilkins (1987); rice lectin, Wilkins and Raikhel (1989); barley lectin, Lerner and Raikhel (1989); concanavalin A, Carrington ct al. (1985); pea lectin, Higgins et al. (1983)] as well as plant storage proteins such as thaumatin (Edens et al., 1982), napin (Ericson et al., 1986) and 2S albumin (Krebbers et al., 1988), and $\beta$-1,3-glucanase (Shinshi et al., 1988). However, the possible function of these C-terminal peptides remains unclear.

Computer searches of the EMBL DNA sequence databases have not revealed any significant homology of the snowdrop lectin sequence with any other protein. Comparison of the protein sequence of the snowdrop lectin with several mannose-binding lectins isolated from plants [e.g. Canavalia, Wang et al. (1975); pea, Higgins et al. (1983); lentin, Foriers et al. (1981)] or rat serum and liver (Ikeda et al., 1987; Drickamer et al., 1986) or $E$. coli (Klemm, 1984) indicated only about $20 \%$ indentity. However, three mannose-specific bulb lectins isolated from showdrop, daffodil and amaryllis belonging to the same family Amaryllidaceae showed high similarity among each other (approximately $80-89 \%$ ) (I. J. Goldstein, unpublished results).

This work was supported in part by grant GM 29470 from the National Institute of Health and grants of the Nationale Bank and the National Fund for Scientific Research (Belgium, FGWO grant
2005989 N). W. P. is Research Director and E. V. D. Research Assistant of this fund. We would like to thank Prof G. Preaux and Dr C. De Greef for their help with the translation experiments in Xenopus oocytes. Furthermore, we are most grateful to Drs N. De Clercq, Dr F. Claessens and Dr K. Hemschoote for their advice in molecular cloning experiments and to V. Feytons and R. De Greef for their expert technical assistance, and Ms L. Loesel and K. Mountjoy for assistance in protein sequencing.

\section{REFERENCES}

Balzarini, J., Schols, D., Neyts, J., Van Damme, E., Peumans, W. \& De Clercq, E. (1990) Antimicrob. Agents Chemother. 35, 410416 .

Bassuner, R., Huth, A., Manteuffel, R. \& Rapoport, T. (1983) Eur. J. Biochem. 133, 321-326

Boston, R. S., Miller, T. J., Mertz, J. E. \& Burgess, R. R. (1982) Plant Physiol. 69, 150-154

Carrington, D. M., Auffret, A. \& Hanke, D. E. (1985) Nature 313. $64-67$.

Colman, A. \& Morser, J. (1979) Cell 17, 517-526.

Drickamer, K., Dordal, M. S. \& Rcynolds, L. (1986) J. Biol. Chem. $261,6878-6887$.

Edens, L., Heslinga, L., Klok, R., Ledeboer, A. M., Maat, J., Toonen. M. Y., Visser, C. \& Verrips, C. T. (1982) Gene 18, 1-12.

Ericson, M. L., Rodin, J., Lenman, M., Glimelius, K., Josefsson, L.G. \& Rask, L. (1986) J. Biol. Chem. 261, 14576-14581

Etzler. M. E. (1986) in The lectins: properties, functions and applications in biology and medecine (Liener. I. E., Sharon, N. \& Goldstein, I. J., eds) pp. 371-435, Academic Press Inc.

Finkelstein, R. R. \& Crouch, M. L. (1986) Plant Physiol. 81, $907-$ 912.

Foriers, A., Lebrun, E., Van Rapenbusch, R., de Neve, R. \& Strosberg, A. D. (1981) J. Biol. Chem. 256, 5550-5560.

Fujiwara, M., Ishida, Y., Nimura, N., Toyama, A. \& Kinoshita, T. (1987) Anal. Biochem. 166, 72-78.

Higgins, T. J. V., Chandler, P. M., Zurawski, G., Button, S. C. \& Spencer, D. (1983) J. Biol. Chem. 258, 9544-9549.

Ikeda, K., Sannoh, T., Kawasaki, N., Kawasaki, T. \& Yamashina, I. (1987) J. Biol. Chem. 262, $7451-7454$

Klemm, P. (1984) Eur. J. Biochem. 143, 395-399.

Krebbers, E., Herdies, L.. De Clercq, A., Seurinck, J., Leeman, J., Van Damme, J., Segura, M., Gheysen, G., Van Montagu, M. \& Vandekerckhove, J. (1988) Plant Phvsiol. 87, 859-866.

Laemmli, U. K. (1970) Nature 227, $680-685$

Lane, C. D. (1981) Cell 24, 281-282.

Larkins, B. A., Pedersen, K., Handa, A. K., Hurkman. W. J. \& Smith, L. D. (1979) Proc. Natl Acad. Sci. USA 76, 6448-6452.

Lerner, D. R. \& Raikhel, N. V. (1989) Plant Physiol. 9l, 124-129.

Mierendorf, R. C. \& Pfeffer, D. (1987) Methods Enzymol. 152, $556-$ 562.

Peumans, W. J., Carlier, A. R. \& Delaey, B. M. (1980) Plant Physiol $66,584-587$.

Peumans, W. I., Stinissen, H. M., Tierens, M. \& Carlier, A. R. (1982) Plant Cell Rep. 1, 212-214.

Raikhel, N. V.\& Wilkins, T. A. (1987) Proc. Natl Acad. Sci. USA 84, $6745-6749$

Sanger, F., Nicklen, S. \& Coulson, A. R. (1977) Proc. Natl Acad. Sci. USA 74, 5463-5467.

Shibuya, N., Berry, J. E. \& Goldstein, 1. J. (1988) Arch. Biochem. Biophys. 267, 676-680.

Shields, D. \& Blobel, G. (1978) J. Biol. Chem. 253, 3753-3756.

Shinshi, H., Wenzler, H., Neuhaus, J.-M., Felix, G., Hofsteenge, J. \& Meins, F. Jr (1988) Proc. Natl Acad. Sci. USA 85, 5541 - 5545.

Siflow, C. D., Hammett. J. R. \& Key, J. L. (1979) Biochemistry 18. $2725-2731$

Swank, R. T. \& Munkres, K. D. (1971) Anal. Biochem. 39, 462-477.

Van Damme, E. J. M., Allen, A. K. \& Peumans, W. J. (1987) FEBS Lett. 215, 140-144.

Van Damme, E. J. M. \& Peumans, W. J. (1988) Plant Physiol. 86, $922-926$. 
Van Damme, E. J. M., Allen, A. K. \& Peumans, W. J. (1988) Physiol. Plant. 73, 52-57.

Van Damme, E. J. M. \& Peumans, W. J. (1990) Planta 182, 605609.

Van Der Wilden, W., Gilkes, N. R. \& Chrispeels, M. J. (1980) Plant Physiol. 66, 390-394.
Von Heijne, G. (1986) Nucleic Acids Res. 14, 4683-4690.

Wang. J. L., Cunningham. B. A., Waxdal, M. J. \& Edelman, G. M. (1975) J. Biol. Chem. 250, 1490--1502.

Wilkins, T. A. \& Raikhel, N. V. (1989) The Plant Cell 1, $541-549$ 